\title{
The Hypocrea jecorina (Trichoderma reesei) hypercellulolytic mutant RUT C30 lacks a 85 kb (29 gene-encoding) region of the wild-type genome
}

\author{
Verena Seidl $^{\dagger}$, Christian Gamauf ${ }^{\dagger}$, Irina S Druzhinina, Bernhard Seiboth, \\ Lukas Hartl and Christian P Kubicek*
}

Address: Research Area Gene Technology and Applied Biochemistry, Institute of Chemical Engineering, Vienna University of Technology, Getreidemarkt 9/166-5, A-1060 Wien, Austria

Email: Verena Seidl - vseidl@mail.zserv.tuwien.ac.at; Christian Gamauf - lgamauf@mail.zserv.tuwien.ac.at; Irina S Druzhinina -druzhini@mail.zserv.tuwien.ac.at; Bernhard Seiboth - bseiboth@mail.zserv.tuwien.ac.at; Lukas Hartl - lhartl@mail.zserv.tuwien.ac.at; Christian P Kubicek* - ckubicek@mail.zserv.tuwien.ac.at

* Corresponding author †Equal contributors

Published: II July 2008

BMC Genomics 2008, 9:327 doi:10.1|86/|47|-2164-9-327
Received: 28 October 2007

Accepted: II July 2008

This article is available from: http://www.biomedcentral.com/I47I-2164/9/327

(c) 2008 Seidl et al; licensee BioMed Central Ltd.

This is an Open Access article distributed under the terms of the Creative Commons Attribution License (http://creativecommons.org/licenses/by/2.0), which permits unrestricted use, distribution, and reproduction in any medium, provided the original work is properly cited.

\begin{abstract}
Background: The hypercellulolytic mutant Hypocrea jecorina (anamorph Trichoderma reesei) RUT $\mathrm{C} 30$ is the $H$. jecorina strain most frequently used for cellulase fermentations and has also often been employed for basic research on cellulase regulation. This strain has been reported to contain a truncated carbon catabolite repressor gene crel and is consequently carbon catabolite derepressed. To date this and an additional frame-shift mutation in the glycoprotein-processing $\beta$ glucosidase II encoding gene are the only known genetic differences in strain RUT C30.

Results: In the present paper we show that $H$. jecorina RUT C 30 lacks an 85 kb genomic fragment, and consequently misses additional 29 genes comprising transcription factors, enzymes of the primary metabolism and transport proteins. This loss is already present in the ancestor of RUT C30 - NG 14 - and seems to have occurred in a palindromic AT-rich repeat (PATRR) typically inducing chromosomal translocations, and is not linked to the crel locus. The mutation of the crel locus has specifically occurred in RUT C30. Some of the genes that are lacking in RUT C30 could be correlated with pronounced alterations in its phenotype, such as poor growth on $\alpha$-linked oligoand polyglucosides (loss of maltose permease), or disturbance of osmotic homeostasis.
\end{abstract}

Conclusion: Our data place a general caveat on the use of $H$. jecorina RUT C30 for further basic research.

\section{Background}

In modern biotechnology, many of the fermentations producing high volume/low price products make use of microbial strains which have been improved by classical mutagenesis using UV light or mutagenic chemicals. Information about the loci which became altered in the process of mutation and selection for improved product formation is scarce, if available at all. One notable exception is penicillin production by the fungus Penicillium chrysogenum [1-3], where the early mutation program has been shown to have removed detoxification reactions for the side chain precursor and has increased the biosyn- 
thetic capacity by amplification of the gene cluster for its production. In the case of the industrial cellulase producing fungus Trichoderma reesei, the anamorph of the pantropical ascomycete Hypocrea jecorina, all of the strains that are currently used on a commercial scale have been ultimately derived from one single isolate which was collected on the Solomon Islands during World War II $[4,5]$. The genetic basis of the respective mutations which led to enhanced cellulase production in these industrial strains is essentially unknown. However, B.S. Montenecourt and D.E. Eveleigh prepared two separate lines of mutants which led to the hypercellulolytic strains RUT C30 and RL-P37 ([5]; Fig. 1), of which H. jecorina RUT C30 has become the most frequently used strain for laboratory cellulase production [6-11]. In this strain two of its genetic changes have been described: one is a truncation in the cre 1 gene encoding CRE1 the carbon catabolite repressor protein, which renders this strain carbon catabolite derepressed [12]; and another one leading to a frameshift mutation in the glycoprotein processing $\beta$-glucosidase II encoding gene [13]. Electrophoretic karyotyping showed that the two largest chromosomes in RUT C30 are somewhat smaller, whereas the other five chromosomes are somewhat larger, resulting in a total increase in genome size from 32.5 to $34.7 \mathrm{Mbps}$ [14]. Gene mapping revealed a history of significant recombination events between the seven chromosomes, but no gene losses were observed so far $[14,15]$. The only exception that was noted was the absence of hybridization of one random clone (RC16) in
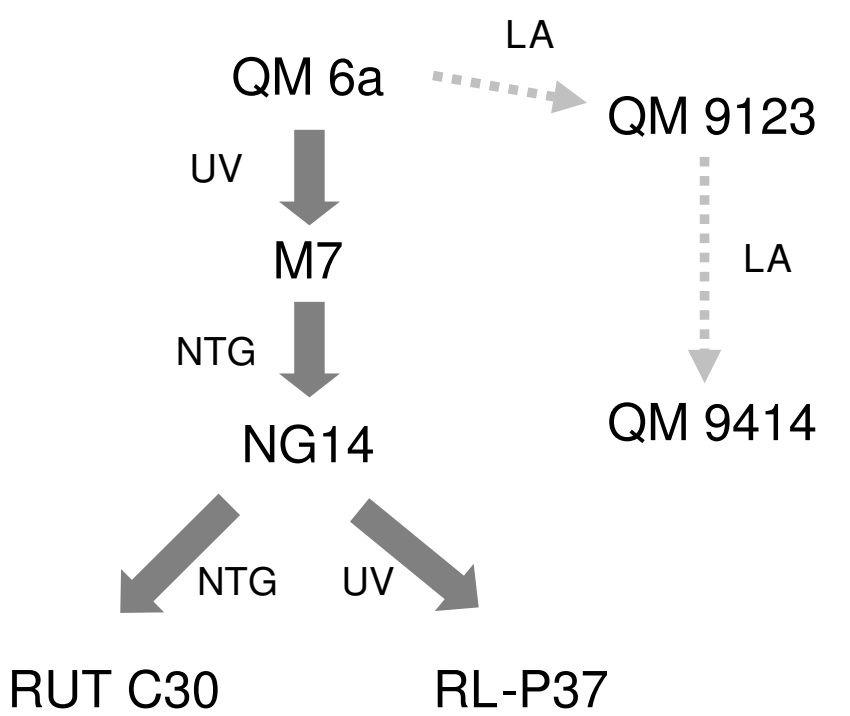

\section{Figure I}

Pedigree of strain $H$. jecorina RUT C30 and its relationship to the wild-type isolate QM6a. Mutations into the strains were introduced by UV-light (UV), nitrosoguanidine (NTG) or linear accelerator (LA). The lineage leading to strain QM 9414 is also shown for comparison.
RUT C30, which hybridized to chromosome IV in strain QM6a and chromosome I in strain QM9414 [14]. This suggests the presence of many more changes in RUT C30, which have not been uncovered until today.

Due to its carbon catabolite derepressed phenotype, $H$. jecorina RUT C30 has frequently been used as a reference strain in studies on the regulation of gene expression [1618] or cell biology [19]. In a similar type of study, we have recently observed that the transcript of a gene was completely absent from RUT C30, and subsequently we found that also the gene was absent from this strain (Christian Gamauf, Christian P. Kubicek and Bernhard Seiboth, unpublished data). In the attempt to identify the reason for the absence of this gene, we discovered that $H$. jecorina RUT C30 lacks a large ( $85 \mathrm{~kb}$ ) segment of genes present on scaffold 15 of the genomic sequence of the wild-type strain H. jecorina QM6a http://genome.jgi-psf.org/Trire2/ Trire2.home.html, [20]. The identification of these genes, and their correlation with changes in the phenotype of $H$. jecorina RUT C30 compared to strains QM6a and QM9414, are reported in this paper.

\section{Methods}

\section{Fungal Strains and culture conditions}

The Hypocrea jecorina strains QM6a (wild-type; ATCC 13631), QM9414 (early cellulase overproducing mutant; ATCC 26921), NG 14 (ATCC 56767) and RUT C30 (ATCC 56765) were used throughout this study. They were maintained on PDA slants (potato dextrose agar; Difco, Franklin Lakes, NJ, USA), and stock cultures kept at $-80^{\circ} \mathrm{C}$.

For shake flask cultures, $200 \mathrm{ml}$ of Mandels Andreotti (MA) medium [21] with carbon sources added as given at the respective results sections, was suspended into $1 \mathrm{~L}$ Erlenmeyer flasks, inoculated with $5 \times 10^{7}$ spores, and incubated on a rotary shaker at $28^{\circ} \mathrm{C}$ and $200 \mathrm{rpm}$. To induce polyol dehydrogenases, glycerol $1 \%(\mathrm{w} / \mathrm{v})$ was used as a carbon source. Cultures were harvested after 24 hrs by gentle filtration, and replaced onto fresh MA medium with either L-arabinose, erythritol or xylitol as an inducer $(10 \mathrm{mM})$, and incubated for further $12 \mathrm{hrs}$. At this time they were harvested and used to prepare cell-free extracts (see below).

\section{Detection production of antimicrobial agents}

Secretion of potential antimicrobial polyketides was tested by an agar diffusion method and plate confrontation tests. For the former, culture filtrates from various time points during growth- and stationary phase on D-glucose and lactose as a carbon source were sampled, proteins denatured by heating $\left(100^{\circ} \mathrm{C}, 5 \mathrm{~min}\right)$, and the samples then concentrated to a tenth of their volume in a Speed Vac. They were then filtered through $20 \mu$ filters 
(Millipore, Billerica, MA, USA) and pipetted into $8 \mathrm{~mm}$ holes punched into agar plates containing inocula of Escherichia coli, Bacillus subtilis and Saccharomyces cerevisiae. In the plate confrontation tests, $8 \mathrm{~mm}$ diameter agar plugs of mycelia of the two strains of $H$. jecorina were placed $5 \mathrm{~cm}$ apart from a respective colony of the same microbes. The presence of an antimicrobial component was indicated in both methods by a clearing zone.

\section{Nucleic acid isolation and hybridisation}

Chromosomal DNA and total RNA were isolated as described [22,23]. Standard methods [24] were used for electrophoresis, blotting and hybridization of nucleic acids.

\section{PCR analysis}

The open reading frames described in the results section were amplified from $H$. jecorina QM9414 and RUT C30 genomic DNA using the GoTaq ${ }^{\circledR}$ system (Promega, Madison, WI, USA) with $0.4 \mu \mathrm{M}$ of sequence specific primers (Table 1) and $2 \mathrm{mM} \mathrm{MgCl}_{2}$. The amplification protocol consisted of an initial denaturation step ( 2 min at $95^{\circ} \mathrm{C}$ ) followed by 28 cycles of denaturation $\left(1 \mathrm{~min}\right.$ at $\left.95^{\circ} \mathrm{C}\right)$, annealing (45 $\mathrm{s}$ at the primer specific temperature) and elongation $\left(2-5 \mathrm{~min}\right.$ at $\left.72^{\circ}\right)$ and was concluded by a final 7 min elongation step $\left(72^{\circ} \mathrm{C}\right)$.

\section{Genome Walking}

To identify the 5' end of the deletion, the GenomeWalker $^{\mathrm{TM}}$ Universal Kit (Clontech, Mountain View, CA, USA; [25]) was used. Briefly, this method first constructs pools of uncloned, adaptor-ligated genomic DNA fragments. Then, two PCR amplifications are preformed per library: the first uses the outer adaptor primer (AP1, provided by the manufacturer) provided in the kit and the outer, gene-specific primer (GWRUT C30gsp1; Table 1). The resulting PCR mixture is then used as a template for a secondary or "nested" PCR with the nested adaptor primer (AP2, provided by the manufacturer) and the nested gene-specific primer (GWRUT C30gsp2; Table 1). The DNA fragments were then cloned and sequenced. PCR amplifications were performed using the Long PCR Enzyme Mix (Fermentas, St.Leon-Rot, Germany). Distinct PCR products were amplified from libraries constructed with DraI and StuI endonucleases and sequenced (MWG Biotech, Ebersberg, Germany).

\section{Amplification and sequencing of the crel locus in $\mathbf{H}$. jecorina RUT C30}

The wild-type H. jecorina cre 1 locus is located on scaffold 2 , and its open reading frame (ORF) spans from 786955789433 (ID 120117). Oligonucleotides used for the amplification of the cre1.1 mutation in strain RUT C30 and are given in Table 1.

\section{Enzyme extraction and assays}

Preparation of cell free extracts and assay of xylitol and Larabinitol dehydrogenases was performed essentially as described previously $[26,27]$. Erythritol dehydrogenase was measured in the same way as L-arabinitol dehydrogenase, but using $100 \mathrm{mM}$ erythritol as a substrate.

\section{Microscopical analysis}

Conidida from 7 - 10 day old cultures were collected and suspended in liquid Mandels Andreotti medium [21] containing either $1 \%$ or $10 \%(\mathrm{w} / \mathrm{v})$ glucose and cultivated at $28^{\circ} \mathrm{C}$. $50 \mu \mathrm{l}$ drops of conidial suspension were placed on large cover slips and examined at room temperature by using differential interference contrast optics with a $60 \times$ (1.2 numerical aperture [NA]) water immersion plan apo objective on an inverted Nikon TE2000 microscope (Nikon, Kingston-Upon-Thames, UK). Images were captured with a Nikon DXM1200F digital camera and transferred into Adobe Photoshop software (version 10.0; Adobe Systems Inc., San Jose, CA, USA) for further processing.

\section{Biolog Phenotype Microarray analysis}

Global carbon assimilation patterns were investigated using Biolog FF MicroPlate ${ }^{\mathrm{TM}}$ (Biolog Inc., Hayward, CA, USA), using the protocol published recently [28]. Briefly, $H$. jecorina strains were pregrown on $20 \mathrm{~g} \cdot \mathrm{l}^{-1}$ malt extract agar, and $90 \mu \mathrm{l}$ of a conidial suspension from them (75 \pm $2 \%$ transmission at $590 \mathrm{~nm}$ ) dispensed into each of the wells of a Biolog FF MicroPlate ${ }^{\mathrm{TM}}$ (Biolog Inc., Hayward, CA, USA). Inoculated microplates were incubated in the dark at $30^{\circ} \mathrm{C}$, and percent absorbance determined after $12,18,24,36,42,48,66$ and $72 \mathrm{~h}$ at $750 \mathrm{~nm}$. Analyses were repeated at least three times for each strain.

\section{Statistical Analysis}

Basic statistical methods such as multiple regression analysis and analysis of variance (ANOVA) as well as multivariate exploratory techniques (cluster and factor analyses) were performed using STATISTICA 6.1 (StatSoft, Inc., Tulsa, OK, USA) data analysis software system.

\section{Sequence analysis and phylogeny}

The genome sequence of H. jecorina is available [29]. To screen the genome for genes missing in strain RUT C30, the "browse" function was used. Genes are identified by their protein ID number (search $\rightarrow$ gene models $\rightarrow$ protein id). Sequence analysis of the genes identified to be missing in $H$. jecorina RUT C30 was performed with InterProScan [30]) and SMART (/; [31]). Proteins with most similar sequences were identified by BLASTX[32]. For phylogenetic analysis, protein sequences were aligned using ClustalX 1.83 [33], the alignment edited with GenEDOC 2.6 [34] and the phylogenetic analysis performed in MEGA 3.1 [35]. 
Table I: PCR Primers used throughout this work

\begin{tabular}{|c|c|c|c|}
\hline Purpose & Target region & Primer name & Sequence $\left(5^{\prime} \rightarrow 3^{\prime}\right)$ \\
\hline \multirow[t]{28}{*}{ Determination of the are of deletion } & ORF I & rgxistartfw & TAAGTTTAGCTAAGGCAGAG \\
\hline & & rgxistartrv & AAATTAAAGAGGCTAGGCTG \\
\hline & ORF 3 & rgxlorf3fw & ACTCGTATGCTTGACTTTCTG \\
\hline & & rgxlorf3rv & CTATCTTGTTTAACCCAGTCAC \\
\hline & ORF 4 & rgxlorf4fw & СТСTTTACTCAATCGCCGAC \\
\hline & & rgxlorf4rv & CCAACAGCAGATTACGAGAC \\
\hline & ORF 5 & rgxlorf5fw & СTTATCCATTTCCGTGTTCC \\
\hline & & rgxlorf5rv & CTAGAATTCAAAGTCGCCAG \\
\hline & ORF 10 & rgxlorflofw & TATAAGTCTGTTTGGTCCCTG \\
\hline & & rgxlorflOrv & GTATTACTCACGCTTTACCTG \\
\hline & ORF I4 & rgxlorfl $4 \mathrm{fw}$ & TAATAACCCAACСТCTACAC \\
\hline & & rgxlorfl4rv & ACACGAGCAGAATATTAGTC \\
\hline & ORF I5 & rgxlorfl $5 \mathrm{fw}$ & $\begin{array}{l}\text { GTACTCTAGAGACAGAATGGTGGCGCTATCG } \\
\text { TC }\end{array}$ \\
\hline & & rgxlorfl5rv & $\begin{array}{l}\text { GTCAGGATCCAGAGCGGTATCAAGCAGTATC } \\
\text { C }\end{array}$ \\
\hline & ORF 16 & rgxlorfl $6 \mathrm{fw}$ & ATGTCTACCTTACTGGATACTG \\
\hline & & rgxlorfl6rv & CCGTCACATATTACAAGTTCTG \\
\hline & ORF 20 & rgxlorf20fw & ATCCACCTCATCGTTATTCC \\
\hline & & rgxlorf20rv & GTGGTTAAGAACAATGGAGC \\
\hline & ORF 26 & $\operatorname{rgxlorf} 26 \mathrm{fw}$ & GTTGACACCATCTACTGCTG \\
\hline & & rgxlorf26rv & GCTTATCTACGCCGATTCTG \\
\hline & ORF 28 & rgxlorf28fw & GTGTTTAACCATAGCCAGAC \\
\hline & & rgxlorf28rv & TCTAGGTAAGCCTTCAAGAG \\
\hline & ORF 29 & rgxlorf29fw & GAACTCCCTAACTTCATCTCAG \\
\hline & & rgxlorf29rv & CAACCATCTCACTAGACCAC \\
\hline & ORF 3I & rgxlorf3Ifw & TTCTTGTCAACCCAACAGTC \\
\hline & & rgxlorf3Irv & TTTCTACCACCTTTGAGCAG \\
\hline & ORF 34 & rgxlorf34fw & GATACGGTAGATATTCTTCC \\
\hline & & rgxlorf34rv & GAGAGTACATTCTAACTACC \\
\hline \multirow{6}{*}{$\begin{array}{l}\text { Determination of the downstream end of the } \\
\text { deletion }\end{array}$} & +500 & orf3Ido05kFw & GAGGTACAGCGAATACAC \\
\hline & +1000 & orf3IdolkFw & CAGATGGTGTTCAAGTTCTC \\
\hline & +1500 & orf3Idol $5 \mathrm{kFw}$ & CTCTTGCTTCCATCAAATCAG \\
\hline & +2000 & orf3Ido2kFw & CGTCAAGTGTTATGTTGTCC \\
\hline & +2500 & orf3Ido $25 \mathrm{kFw}$ & CGAGATGAAAGATTCACAGC \\
\hline & +3000 & orf3Ido3kFw & GAGGTATCGTGTTCAATGTC \\
\hline \multirow[t]{4}{*}{ Genome Walking } & & GWqm94|4gspl & $\begin{array}{l}\text { ССТТАТСАСТАССТТССАССТССАТСТТАТАС } \\
\text { СС }\end{array}$ \\
\hline & & GWqm94|4gsp2 & ССТССАТСТТАТАСССТСТАСССААТТССС \\
\hline & & GWRUTC30gspl & TACCGCCATCGCAGACTGTTCCCTTTC \\
\hline & & GWRUTC30gsp2 & TCACTATGAGACGGCAG \\
\hline \multirow[t]{5}{*}{ Crel amplification } & & Crelfw & TCTCTGGGCTCTCTTGTAACC \\
\hline & & Crellr & TGCCACTССТССТСАTGTCAT \\
\hline & & creF & GTACTTTGGCCCTCGCTGAG \\
\hline & & creR & CCAGACTGCATAAGGATTCCC \\
\hline & & creRUTr & AGCAATCAGGTGCAGATATCAC \\
\hline
\end{tabular}

\section{Results}

Identification of a genome fragment missing in $\mathrm{H}$. jecorina RUT C30

The starting point of our analysis was a rhamnogalacturonase gene rgx1 (ID 122780) which is located on scaffold 15 in the $H$. jecorina genome database, and which is expressed in $H$. jecorina QM9414 but not in strain RUT C30 (C. Gamauf, C. P. Kubicek and B. Seiboth, unpublished data). Consequently, we tested by PCR whether this gene is actually present in the latter strain. Using the rgx 1 specific primers given in Table 1, a clear product of expected size could be amplified from strain QM9414, 


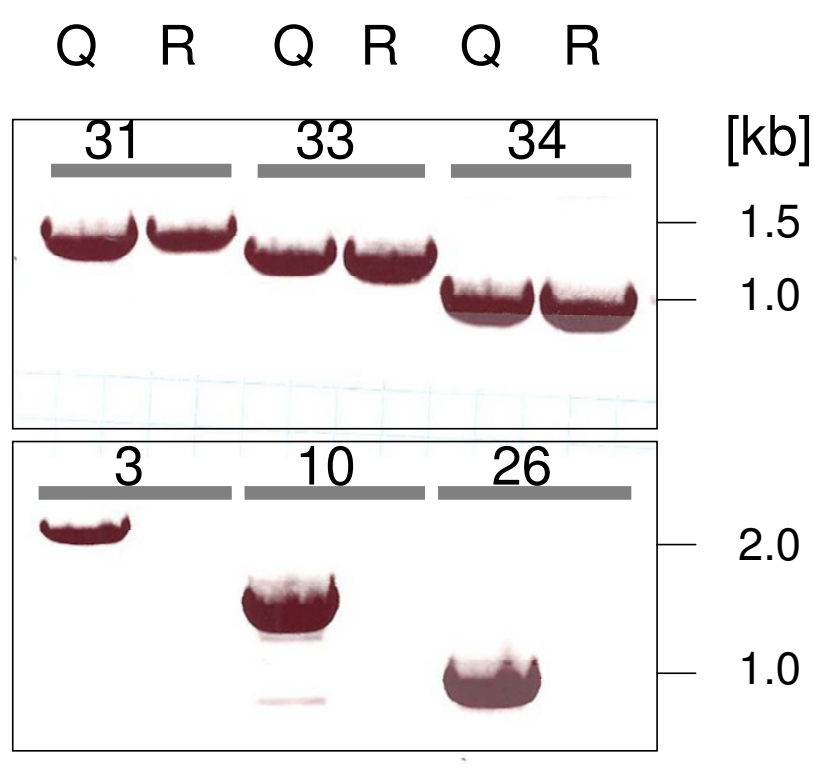

Figure 2

Examples of the PCR strategy used to identify genes lacking in $H$. jecorina RUT C30 but being present in $H$. jecorina QM6a (genome sequence) and QM 9414 (experimental organism): Top row: genes present in both; bottom row: genes absent from RUT C30. Genes amplified are indicated by the ORF no. as given in Tables I and 2. Q indicates strain QM 94I4, R strain RUT C30.

but not from RUT C30 (Fig. 2a). Since this could indicate a gene deletion at this locus, we then designed primers for the amplification of the immediate 5' and 3' flanking genes (i.e. a monocarboxylate transporter, ID 109211; and an aldehyde dehydrogenase, ID 65142; respectively). As these two genes were apparently absent from strain RUT C30 too (Fig. 2b), a larger gene lesion was assumed. Therefore we screened for presence of genes with wider distance from the rgx 1 locus until positive hits were found, and then reduced the intervals until the genes immediately flanking the gap could be identified. Thereby the first gene located 3' of the gap in RUT C30 was identified as a nitrilase, ID 64996. However, no gene could be found in the 5 ' direction of the gap, because even amplification of the most 5 ' located gene on scaffold 15 was not possible in strain RUT C30.

Since these data suggested that the gap may be continued on another, unknown scaffold, we applied a genome walking strategy. Primers were designed to hybridize within the intergenic region between the gene encoding a hypothetical protein, ID 79726, and the gene encoding a nitrilase, ID 64996 (primer GWRUT C30gsp1) and within the coding region of ID 79726 (primer GWRUT
C30gsp2). Interestingly, in contrast to our assumptions, this method identified the 5 ' end of the gap close to the beginning of scaffold 15 in an AT-rich region (at +1555 bp; Fig. 3a). This breakpoint localizes within a large intron in the 5'-half of an ORF encoding a putative rhodaneselike protein ID 109199. This gene displays a high number of unusually long introns (Fig. 3a), and it is possible that these either represent annotation errors or it is a pseudogene. A closer investigation of this gene was beyond the scope of this paper, however.

The 3 ' end of the gap identified by genome walking corresponded to the region identified by PCR amplification and specified it at +86603 bp of scaffold 15 in the 5 ' nontranscribed area of the nitrilase-encoding gene (see above). Thus, this analysis provides evidence that $H$. jecorina RUT C30 contains an approximately $85 \mathrm{~kb}$ large gap on scaffold 15, which in H. jecorina QM6a [20] contains 29 ORFs (Fig. 3b) and that most of these genes are not present in the genome anymore.

\section{The $\mathbf{8 5 - k b}$ deletion is unlinked to the cre I mutation} As the reason for this gene deletion in RUT C30 is unknown, we wondered whether it would be topologically related to the cre 1.1 mutation. The cre 1 locus in this strain has been shown to be truncated [11], but the exact length of the mutation and its genomic location has not yet been reported. A BLAST search of the $H$. jecorina genome sequence database with the cloned cre1 gene identified it to be located on scaffold 2: 786955-789433 (ID 120117), and thus distant from the locus of the lesion which was identified in this paper. In order to identify the cre1.1 mutation, we amplified and sequenced the cre1 locus in strain RUT C30. Using the primers Cre1fw and CreIIr (Table 1), PCR with QM9414 DNA resulted in a 3565 bp fragment as expected, whereas RUT C30 yielded a fragment of 1087 bp only. Sequencing of the fragment obtained with RUT C30, and its alignment with the sequence of scaffold 2 (Fig. 4) revealed the loss of a 2478 bp fragment which starts 3 ' of the region encoding the CRE1 zinc finger and reaches into a noncoding region. The coding region of the immediately following gene (tre12588) was not affected.

\section{In silico identification of the genes lacking in $\mathrm{H}$. jecorina RUT C30}

In order to evaluate the impact of the detected gene losses on the phenotype of $H$. jecorina RUT C30, we first performed a detailed in silico analysis of the encoded putative proteins (Table 2). Most of the ORFs could be aligned with proteins of known function, and only three of them encoded completely unknown proteins. Two genes encoded $\mathrm{Cys}_{6} \mathrm{Zn}$ (II)-type transcription factors, which are only found in fungi [36]. However, orthologues of these two transcription factors have not been described in any 

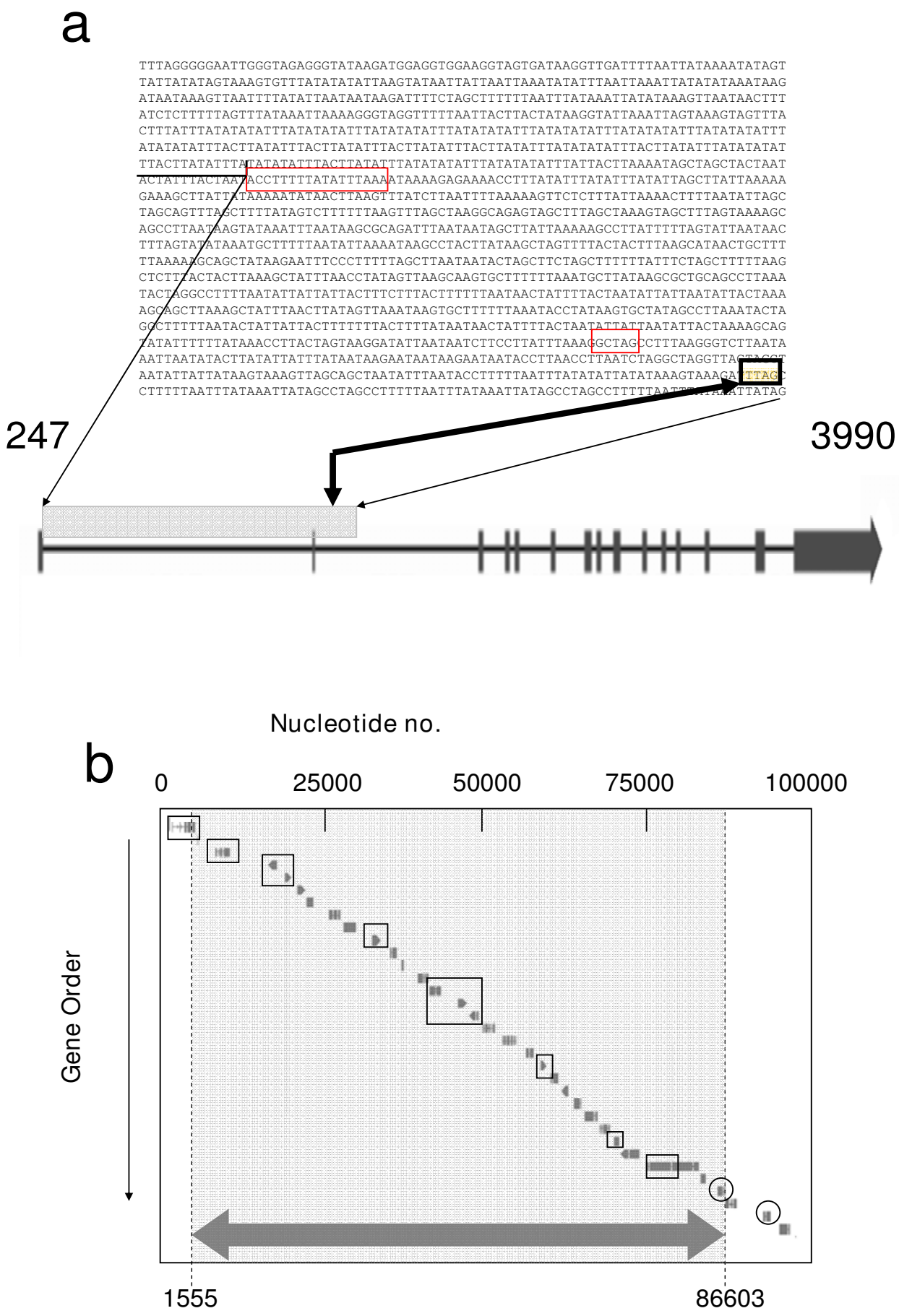

Figure 3

Intron-exon organization of the first gene of scaffold_I5, I5, and nt sequence of its first 1650 bp's. The thin arrows show the location of the depicted $n t$ sequence within the gene. The two short exons are boxed in red. The +1555 breakpoint is indicated by a thick arrow and boxed in black; (b) Scheme of the 5'-part of scaffold I5 of the genome of H. jecorina, and the area missing in strain RUT C30 (indicated by a grey background and the large arrow on the bottom). ORFs in square indicate those, whose absence has also been verified by PCR analysis, ORFs in circles indicate those which were verified to be present, respectively. 


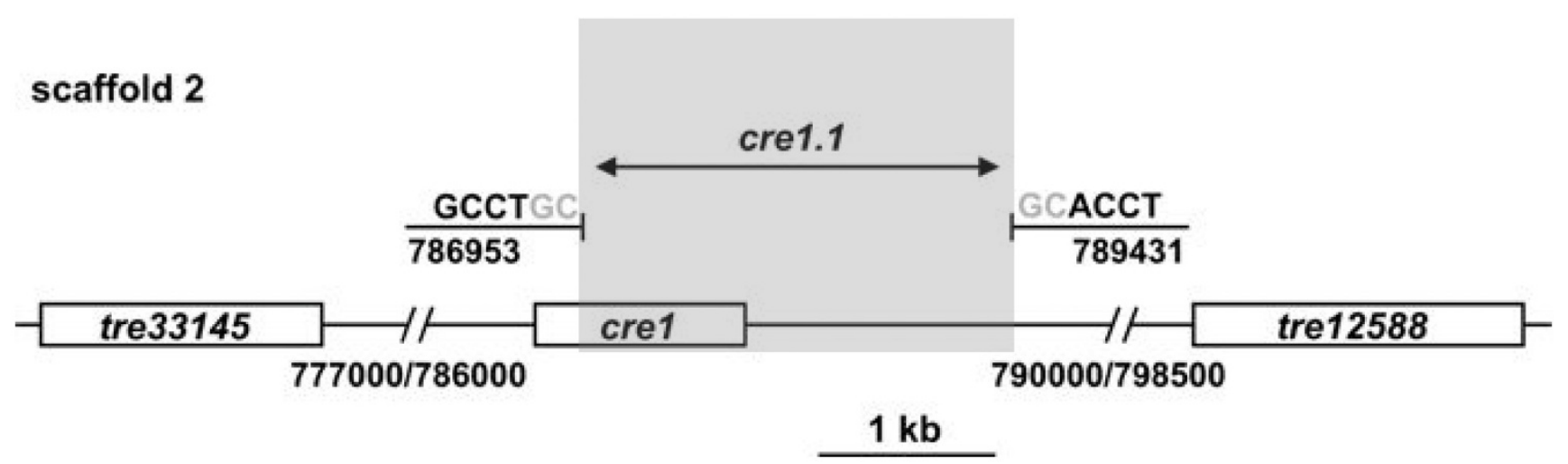

\section{Figure 4}

A comparison of the cre I locus in Trichoderma reesei QM6a and RUT C30. The cre I gene is located on scaffold 2. The respective location of the neighboring genes is also given. The cre I.I mutation in RUT C 30 comprises a region of 2478 bp, which is highlighted by a grey box. The two nucleotides given in grey could not be assigned unambiguously to one of the ends of the gap.

other fungus yet and their specific functions are therefore not known. The majority of the genes missing in $\mathrm{H}$. jecorina RUT C30 encoded enzymes involved in primary metabolism (e.g. two aldehyde dehydrogenases, one aldo/keto reductase, one alcohol dehydrogenase, one glycerol dehydrogenase and one trehalase), and three transporters (a maltose permease, a monosaccharide transporter and an amino acid permease). The latter is very similar to a general amino acid permease that was characterized from Amanita muscaria [37]. Four other genes encoded extracellular enzymes (a glucan endo-1,6$\beta$-glucosidase, a carbohydrate esterase, and the rhamnogalacturonase RGX1 that initially triggered this study). Finally, two of the genes missing in H. jecorina RUT C30 encoded proteins involved in cellular detoxification pathways, namely a multidrug efflux pump and a glutathione $S$ transferase, and gene one encoded a class I reducing polyketide synthase.

\section{H. jecorina RUT C30 is impaired in the assimilation of $\alpha$ - glucans and -glucosides}

The presence of a maltose permease in the missing genomic fragment raised the question whether this would have an impact of the growth of $H$. jecorina RUT C30 on $\alpha$-linked glucans and glucosides. As can be seen from Fig. 5 , growth on dextrin, starch, maltose and maltotriose was indeed strongly impaired in RUT C30, which is consistent with the absence of a maltose permease responsible for $\alpha$ glucoside uptake. This interpretation is supported by the fact that $H$. jecorina - in contrast to several Aspergillus spp. - does not have multiple maltose permease genes (unpublished observations) and also lacks an extracellular $\alpha$-glucosidase [38]. The present findings are therefore consistent with a metabolism of $\alpha$-glucosides in $\mathrm{H}$. jeco- rina by uptake and intracellular hydrolysis, which is impaired in RUT C30.

\section{H. jecorina RUT C30 displays several alterations in carbon source assimilation}

In view of the relatively strong abundance of metabolic genes in the genomic region which is missing in $\mathrm{H}$. jecorina RUT C30, we performed a comprehensive analysis of its ability to assimilate (i.e. grow on) carbon sources using 95 carbon sources contained in the Biolog Phenotype Microarrays, and compared it to its wild-type strain QM6a. The data obtained (Fig. 6) identified several striking differences: strain RUT C30 had a strongly impaired growth on L-arabinose, L-erythritol, D-galactose and also 2-keto-D-gluconic acid. Interestingly, the opposite effect (= an enhancement of the assimilation rate) was also observed with some other carbon sources, e.g. glycerol, $N$ acetyl- $\beta$-D-glucosamine, D-mannitol, D-fructose, D-trehalose, D-mannose, D-ribose). This strongly reduced growth on L-arabinose, L-erythritol and also D-galactose suggested to us that one of the aldo/keto-reductases identified as lacking in strain RUT C30 (i.e. ID 65142, ID 6567, and ID 64956) could be involved in polyol assimilation. In order to test this hypothesis, we prepared cell free extracts from strains QM9414 and RUT C30, and tested these activities in cell-free extracts. As shown Table 3, both strains of $H$. jecorina had high $\mathrm{NAD}^{+}$-linked dehydrogenase activities with xylitol, L-arabinitol and erythritol and NADPH-linked dehydrogenase activities with D-xylose and L-arabinose as substrates, respectively. Activities with the other coenzyme (i.e. NADP with xylitol, L-arabinitol and erythritol; and NADH with D-xylose and L-arabinose) were negligible, with the exception of some NADP+linked activity of strain RUT C30 on xylitol, which was 
Table 2: Identification of genes located on the 5' end of scaffold I5*

\begin{tabular}{|c|c|c|c|}
\hline ORF & Location on scaffold & Protein ID & Putative function \\
\hline I & $247-3990$ & 109199 & Rhodanese-like protein \\
\hline 2 & $4265-4550$ & 43418 & Hypothetical protein \\
\hline 3 & $7|35-946|$ & 109201 & FAD-linked oxidase \\
\hline 4 & $15618-16994$ & 64959 & Peptidase S26, signal peptidase \\
\hline 5 & $18217-19356$ & 122778 & Glycerol dehydrogenase GLD2 \\
\hline 6 & $20262-21664$ & 71817 & Multidrug resistance protein \\
\hline 7 & $21775-2284 \mid$ & 62215 & carbohydrate esterase (family 4), imidase \\
\hline 8 & $25282-27 \mid 43$ & 65191 & Maltose permease \\
\hline 9 & $27655-29638$ & 109206 & Heterokaryon incompatibility protein het- 6 \\
\hline 10 & $32246-33596$ & 64906 & Glucan endo-I,6- $\beta$-glucosidase (GH5) \\
\hline 11 & $35024-36114$ & 49946 & Glutathione S-transferase \\
\hline 12 & $36973-37308$ & 65117 & Ankyrin repeat protein \\
\hline 13 & $39475-41248$ & 4726 & Protein of the cytochrome P450 CYP2 family (phenylacetate-2 hydroxylase) \\
\hline 14 & $4 \mid 375-43162$ & $10921 \mid$ & Monocarboxylate transporter \\
\hline 15 & $45898-47405$ & 122780 & Rhamnogalacturonase RGXI \\
\hline 16 & $47630-49314$ & 65142 & Aldehyde dehydrogenase \\
\hline 17 & $49852-51907$ & 64971 & Aromatic and unpolar amino acid permease \\
\hline 18 & $52993-55245$ & 71823 & Cys6-transcription factor \\
\hline 19 & $56788-58016$ & 6567 & Aldo-keto reductase \\
\hline 20 & $59|25-6008|$ & 65097 & Alcohol dehydrogenase \\
\hline 21 & $60755-61994$ & 79725 & Cys6-transcription factor \\
\hline 22 & $624 \mid I-63580$ & 65041 & N2, N2-dimethylguanosine tRNA methyl transferase \\
\hline 23 & $64486-65668$ & 64956 & Aldehyde dehydrogenase \\
\hline 24 & $66149-68189$ & 109219 & Hypothetical protein, poorly conserved \\
\hline 25 & $68498-70244$ & 65036 & Cytochrome P450-dependent alkane hydroxylase \\
\hline 26 & $70809-7 \mid 776$ & 109221 & Unknown protein, poorly conserved \\
\hline 27 & $71889-74905$ & 25224 & Acid trehalase GH65 \\
\hline 28 & $76106-84410$ & 65172 & Polyketide synthase class I, reducing \\
\hline 29 & $84689-85537$ & 79726 & Hypothetical protein, well conserved \\
\hline 30 & $87457-88602$ & 64996 & Nitrilase \\
\hline 31 & $88689-90473$ & 122783 & Cys6 transcription factor \\
\hline 32 & $94737-95939$ & 65039 & Sexual development inhibiting protein LsdA \\
\hline 33 & $97256-98976$ & 65070 & Cys6 transcription factor \\
\hline 34 & $101185-102595$ & 65190 & Nitrilase \\
\hline
\end{tabular}

* Genes I-29 are are missing from $H$. jecorina RUT C30

absent from strain QM9414. In general, activities in strain RUT C30 were significantly higher. Only the NAD+-linked erythritol dehydrogenase activity was similar in both strains. These data indicate that the loss of the three aldo/ ketoreductases in RUT C30 has apparently no effect on its metabolism of the major polyols and therefore cannot explain the different growth pattern of strain RUT C30 on L-arabinose and L-erythritol

\section{H. jecorina RUT C30 favors high osmotic pressure}

The glycerol dehydrogenase GLD2; EC 1.1.1.156; [39]), which is lacking in $H$. jecorina RUT C30, has been shown to be involved in glycerol formation during osmoadaptation in A. nidulans [40] and $H$. atroviridis ([41]; there named GLD1). We were therefore interested to see whether the loss of glycerol dehydrogenase would render strain RUT C30 osmotically unstable. We grew strains QM9414 and RUT C30 in submerged culture on 1 and $10 \%(\mathrm{w} / \mathrm{v})$ glucose. The results are shown in Fig. $7 \mathrm{a}$ : strain
RUT C30 had a longer lag phase for growth but then accumulated about double the concentration of biomass than strain QM9414 under both conditions. The conversion yield $\mathrm{Y}_{\mathrm{X} / \mathrm{S}}$ on $1 \%(\mathrm{w} / \mathrm{v})$ glucose was 0.45 and 0.63 for strain QM9414 and RUT C30. While a yield over 0.5 can be explained by the utilization of amino acids in peptone for biomass formation [42], these data show that RUT C30 accumulates biomass more efficiently under both conditions. Yields on $10 \%(\mathrm{w} / \mathrm{v})$ glucose were 0.08 and 0.22 , respectively. This indicated that the loss of glycerol dehydrogenase did not render strain RUT C30 osmotically labile, but that it even performed better than strain QM9414 at high osmotic pressure.

\section{Spore volume increase during germination in $\mathbf{H}$. jecorina RUT C30}

In order to learn the reason for the prolonged lag phase in strain RUT C30, we microscopically examined the germination of its spores. This analysis revealed that RUT C30 

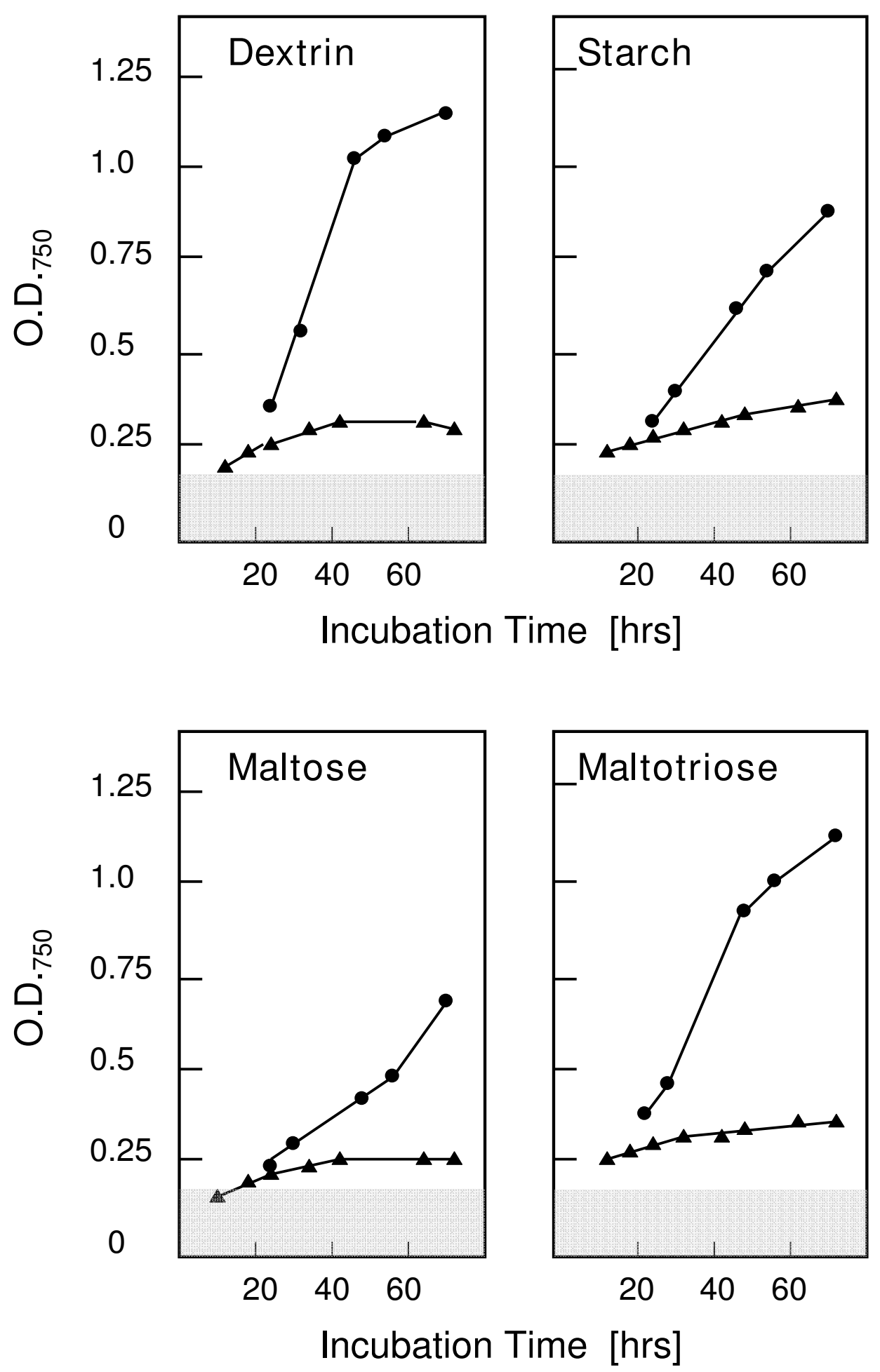

Figure 5

Growth rates of $H$. jecorina strain QM6a (full circles) and strain RUT C30 (full triangles) on maltose, maltotriose, dextrin and starch, using the Biolog phenotype arrays system. The grey area indicates the threshold of the water control. Data are shown are means of 3 separate experiments, which differed by less than \pm 10 relative \%. 


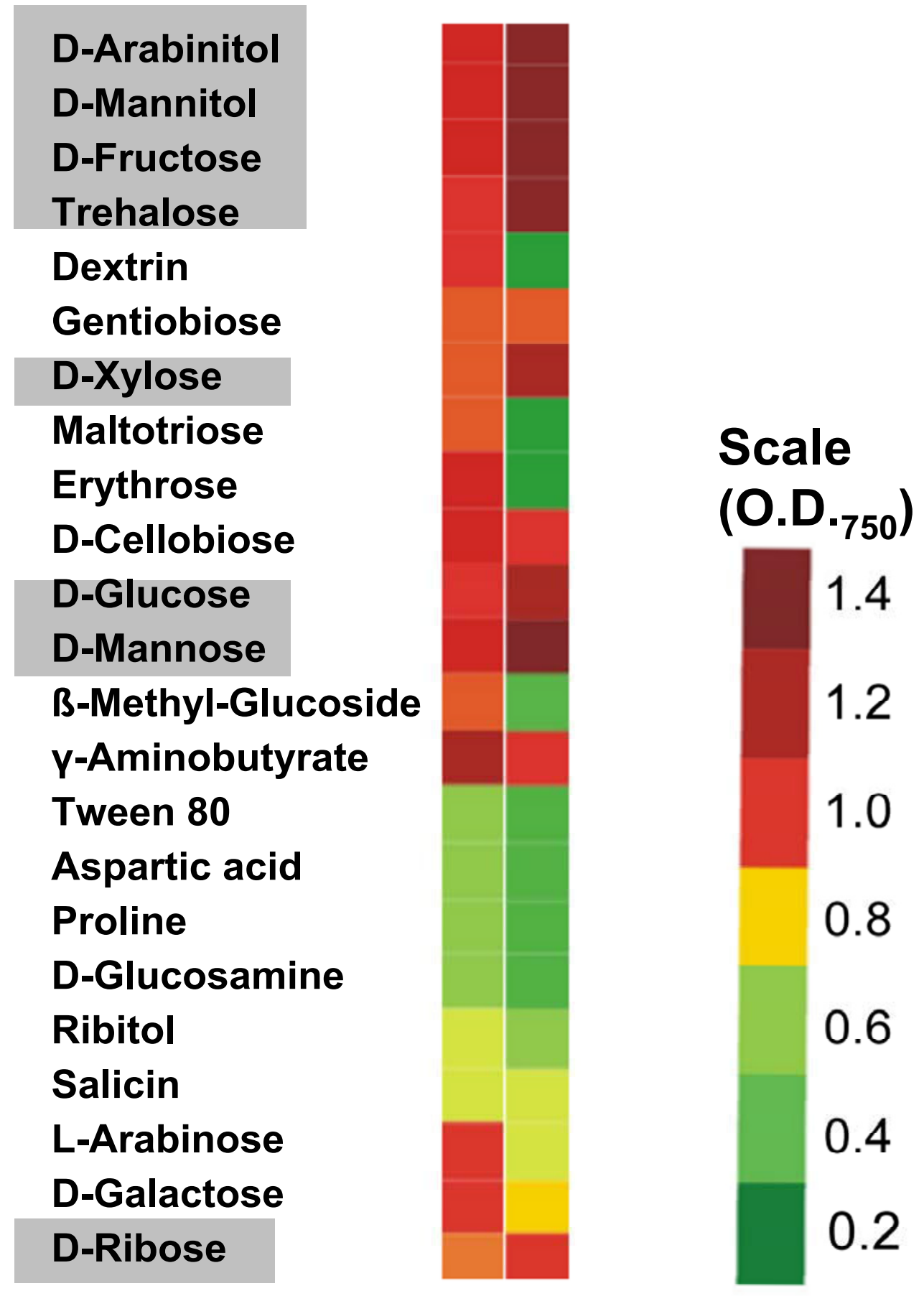

Figure 6

Phenotype array analysis of carbon source profiles of $H$. jecorina QM6a (Q)and RUT C30 (R). Only carbon sources where a difference to the parent strain QM6a was found are shown, and given in a color code. The OD 750 refers to measurements at $48 \mathrm{hrs}$ of growth, at which time the value is proportional to the growth rate $\left(O D_{750} / \mathrm{h}\right)$ of the fungus on the respective carbon source. Carbon sources which are highlighted by a grey background are those which result in higher growth rates in RUT C30. 
Table 3: Polyol dehydrogenase activities in H. jecorina QM 9414 and RUT C30

\begin{tabular}{|c|c|c|c|c|c|c|c|c|}
\hline & \multicolumn{2}{|l|}{ NAD } & \multicolumn{2}{|l|}{$\mathrm{NADH}$} & \multicolumn{2}{|l|}{ NADP } & \multicolumn{2}{|l|}{ NADPH } \\
\hline & QM94I4 & RUT C30 & QM94I4 & RUT C30 & QM94I4 & RUT C30 & QM94I4 & RUT C30 \\
\hline D-Xylose & & & $0.03[ \pm 0,025]$ & $0.09[ \pm 0.01]$ & & & $0.52[ \pm 0.03]$ & $2.5 \mid[ \pm 0.04]$ \\
\hline xylitol & I.I [ \pm 0.05$]$ & $2.4[ \pm 0.3]$ & & & $<0.005$ & $0,14[ \pm 0.02]$ & & \\
\hline L-arabinose & & & $0.018[ \pm 0.01]$ & $0,021[ \pm 0.006]$ & & & $0.3[ \pm 0.02]$ & $1.15[ \pm 0.03]$ \\
\hline L-arabinitol & $0.45[ \pm 0.03]$ & $0.75[ \pm 0.05]$ & & & $<0.005$ & $0.05[ \pm 0.01]$ & & \\
\hline erythritol & $0.23[ \pm 0.04]$ & $0.25[ \pm 0.04]$ & & & $<0.005$ & $<0.005$ & & \\
\hline
\end{tabular}

Components given in the first row were used as substrates, and the respective activities with $N A D(P)$ or $N A D(P) H$ are given in the rows under the respective coenzymes and strains. Open positions indicate that the experiment has not been done.

spores first undergo considerable swelling and increase in size before they start to form a germ tube (Fig. 8). While spores of $H$. jecorina QM9414 showed a uniform spore diameter of $6-10 \mu \mathrm{m}$ during spore germination, $\mathrm{H}$. jecorina RUT C30 spores swelled up to a diameter of $20-30$ $\mu \mathrm{m}$, corresponding to an up to 50 - fold increase of spore volume (Fig. 8a-d). Interestingly, not all RUT C30 spores showed a swelling response and the extent of the swelling varied, resulting in a relatively homogenous distribution of spore diameters from ca. 10 to $25 \mu \mathrm{m}$. Germination was observed from swollen and not swollen spores and osmotic stress (10\% carbon source) did delay germination but not influence the ratio of swollen to not swollen spores. However, although germination from even extremely swollen spores was observed, apparently not all

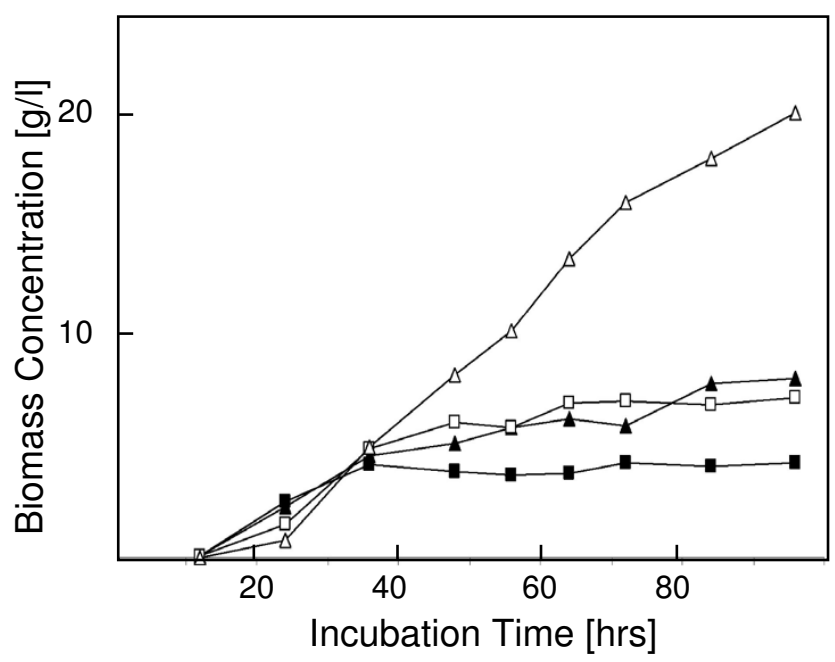

\section{Figure 7}

Biomass formation of $H$. jecorina QM6a (full symbols) and RUT C30 (empty symbols) under osmotic stress evoked by $10 \%$ glucose. (a) growth pattern in submerged culture on $1 \%(\mathrm{w} / \mathrm{v})$ and $10 \%$ glucose $(\mathrm{w} / \mathrm{v})$ (squares and triangles, respectively). Values are from a single experiment, but data consistent with the claims made were obtained in at least two further experiments. swollen spores were able to enter the germination phase and during later growth stages a number of large spores that had undergone autophagic cell death [43] could be detected (Fig. 8e). The spore swelling and autophagy of swollen spores in $H$. jecorina RUT C30 could result in a delay of the formation of an interconnected mycelium and therefore explain the observed prolonged lag phase of RUT C30.

\section{H. jecorina RUT C30 lacks pigment formation}

An intriguing observation during the cultivation experiments was that strain RUT C30 does not form the yellow pigment, which is characteristic for $H$. jecorina and other Trichoderma spp. from section Longibrachiatum [44]. This difference was observed both in late submerged cultures as well as during plate growth. We suspected that this could be due to the absence of the class I polyketide synthase ID 65172. In order to test this presumption, we subjected its amino acid sequence to phylogenetic analysis (NJ) with other polyketide synthases investigated by Kroken et al. [45]. In this analysis (data not shown), the $H$. jecorina polyketide synthase was determined to be member of clade I from the reducing polyketide synthases, thereby clustering most closely to Bipolaris mayidis PKS5, whose function is not known. Since none of the members of this cluster is known to be responsible for pigment formation, but some of them (e.g. the lovastatin synthase) synthesize antimicrobial polyketides, we also tested whether RUT C30 would be deficient in formation of an antimicrobial compound. However, using the agar diffusion assay and the confrontation assay, we could not detect any such compound in strain QM9414 and consequently also not in RUT C30 (data not shown). While the use of more sensitive methods such as MS may detect differences in secondary metabolite production between $H$. jecorina QM6a and RUT C30, our data show that the loss of this class I polyketide synthase does not influence the antimicrobial activity of $H$. jecorina. 

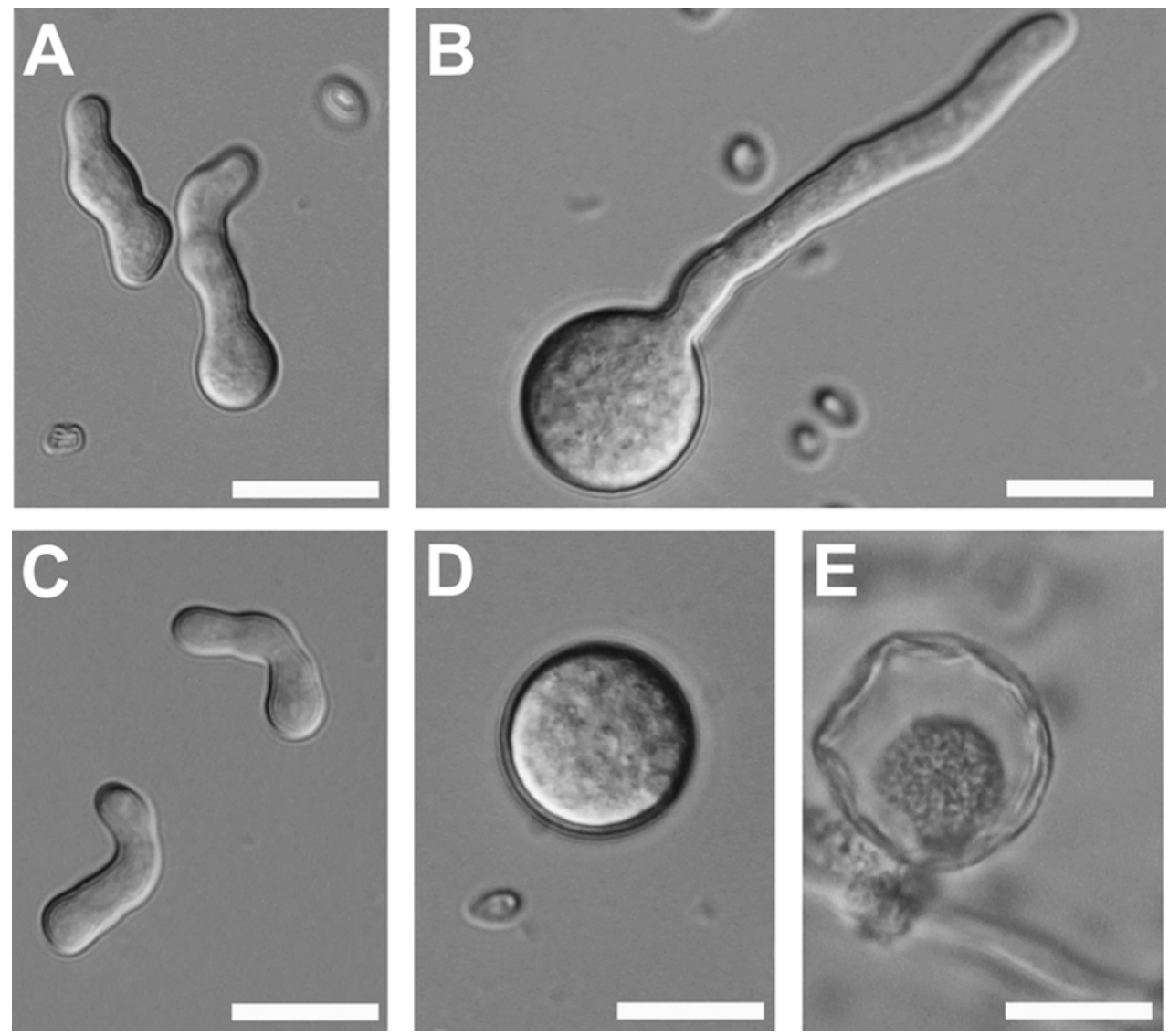

\section{Figure 8}

DIC images of spore germination of $H$. jecorina grown in liquid medium with I\% glucose: (a) QM94 I4 and (b) RUT C30 and cultires grown under osmotic stress with $10 \%$ glucose: (c) QM94 I4 and (d) RUT C30. (e) Swollwn RUT C30 spores that were unable to germinate underwent autophagic cell death. Bars $=20 \mu \mathrm{m}$.

\section{H. jecorina NG I4 has a full-size cre I but lacks the $85 \mathrm{~kb}$ fragment}

Both, H. jecorina RUT C30 and its ancestor NG 14, are mutants that underwent mutagenesis by nitrosoguanidin and were selected for growth on cellulose in the presence of glycerol (NG 14) and 2-desoxiglucose (RUT C30). We therefore wondered whether the loss of the $85 \mathrm{~kb}$ fragment and the truncation of cre 1 were the result of one or both of these mutation steps.

In order to test the presence of the full-length or the truncated cre1 gene in NG 14, we designed primers creF and creR (table 1). CreR hybridizes in the $2.5 \mathrm{~kb}$ fragment of the cre 1 locus that is absent in RUT C30 (see above) and should therefore result in amplification of a $2.9 \mathrm{~kb}$ fragment from the native cre 1 gene only. Using these primers we could amplify the expected PCR product from QM9414 and NG 14 but not from RUT C30 (Fig. 9a). On the other hand using primer creF in combination with primer creRUTr, binding downstream of the cre 1 truncation, we amplified a $1.9 \mathrm{~kb}$ fragment corresponding to the truncated cre1.1 gene from RUT C30, whereas the two other strains yielded a larger $(4.4 \mathrm{~kb})$ fragment corresponding to the native genomic locus (Fig. 9b). Consequently, we conclude that the cre1 truncation specifically occurred in H. jecorina RUT C30.

In order to test for the presence or absence of the $85-\mathrm{kb}$ gene fragment, which is missing in RUT C30, the gene specific primers for ORFs 3, 4, 5, 10, 20 and 26 (table 1) were used. By means of these primers, we were unable to amplify a PCR product from strains NG 14 and RUT C30, whereas amplicons were obtained in the control with QM9414 (data not given), indicating that the large chromosome lesion is already present in the ancestor of RUT C30. 


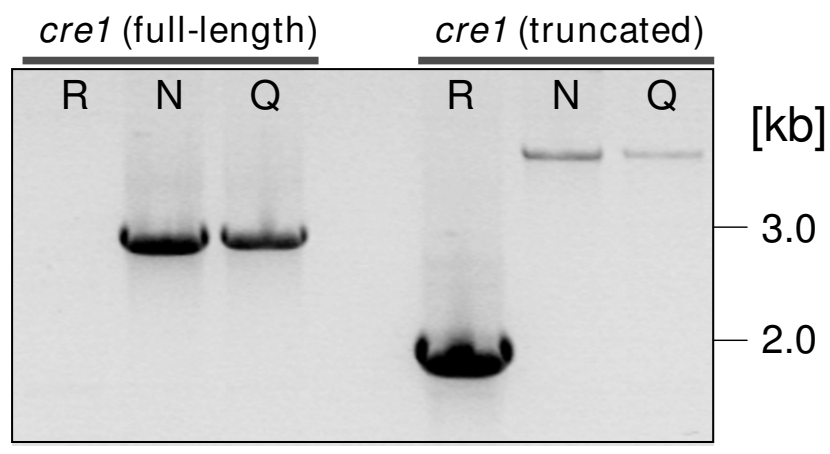

Figure 9

Analysis of cre l in $\mathrm{H}$. jecorina RUT C30, NG 14 and QM94I 4 by PCR. Primers (given in table I) used for 'cre I (full length)' were designed to form a PCR product $(2.9 \mathrm{~kb})$ only if the full length version of the gene is present but no PCR product for the truncated cre $I$ version detected in strain RUT C30. For 'crel (truncated)' the reverse primer was localized downstream of the cre I gene, resulting in the formation of a $1.9 \mathrm{~kb}$ PCR product if a truncated cre $I$ gene was present in the genome and a 4.4 $\mathrm{kb}$ fragment if for full-length cre I. R indicates strain RUT C30, N strain NG I4 and Q strain QM94I4.

\section{Discussion}

In the present work we have shown that the hypercellulolytic mutant $H$. jecorina RUT C30, in which only two mutations (in the carbon catabolite repressor protein CRE1 and the processing $\beta$-glucosidase II $[12,13]$ had been described so far, carries a major deletion in its genome which comprises 85.048 bp including 29 open reading frames. Although this finding had not been detected so far, it is in accordance with earlier karyotyping results, which showed that the size and number of chromosomes in $H$. jecorina strain RUT C30 differed significantly from QM6a and QM9414 [14,15]. Unfortunately, none of the marker genes that were used in these studies was located on scaffold 15, and we were thus unable to identify the chromosome on which the $85 \mathrm{~kb}$ fragment described in this paper is lacking. However, despite of the fact that these $0.085 \mathrm{Mbp}$ are a significant lesion, they are small compared to the changes in chromosome size determined by these authors. While the size determination in contour-clamped homogeneous electric field (CHEF) gel is not sensitive enough to distinguish between 0.1 and 0.2 $\mathrm{Mbp}$, it is nonetheless possible that more deletions may be present in the genome of RUT C30.

The reason for this gene loss in RUT C30 is unclear. The genealogy leading to mutant RUT C30 involved three mutagenesis steps from the wild type strain (Fig. 1), of which the first one was simple UV mutagenesis whereas the subsequent two (from M7 to NG 14, and from NG 14 to RUT C30) involved mutagenesis by N-methyl-N'-nitro-
$\mathrm{N}$-nitrosoguanidine [5]. However, both agents usually do not lead to chromosome alterations or translocations. The results from genome walking have shown that the 5 ' site of the deletion is located in a region containing an about 1600 nt long palindromic AT-rich region (PATRR). PATRRs have been found to mediate genomic instability, thereby contributing to translocations, deletions and amplifications [46,47]. Carter et al. [15] have speculated that the lack of a sexual cycle and the need for mitotic pairing of chromosomes arising from there may increase the tolerance of mitosporic fungi to chromosome rearrangements. In the light of the above reasoning, PATRRs may be preferred regions for this. In $N$. crassa, this has been shown to be due to escape from het-c incompatibility [48]. The possibility that such rearrangements may regularly occur in $H$. jecorina would be consistent with similar data from other fungi [49], and also be consistent with results from the analysis of the genome of $H$. jecorina QM6a [20] which revealed a number of gene conversion events. In addition, such events could also occur during the regeneration of protoplasts after transformation with DNA (as shown for Nectria haematococca [50]), which would explain the high phenotypic diversity in $H$. jecorina transformants [27]. Our results with $H$. jecorina NG 14 show that the loss of the $85 \mathrm{~kb}$ gene fragment already occurred before the origin of RUT C30, and such an event must therefore have taken place in this or even an earlier mutant strain.

The structure of the gene encoding the rhodanese-like protein also supports such a scenario: this gene does not have any orthologues in fungi, but shows similarity to flavibacterial rhodanese-like proteins. It is conceivable that this gene arrived by horizontal gene transfer in an instable region, which led to the insertion to this unsual high number (14) of introns. The gene seems to be active, though, as the database lists 15 ESTs for it.

We were not able to predict the putative function of all genes which have been lost in RUT C30. Although we could therefore not to relate all of these genes to distinct phenotypic properties, for some of them clear correlations were obtained. One of them was the inability to grow on $\alpha$-linked oligo- and polysaccharides, which we interpret to be due to the loss of the maltose permease gene (ID 65191). This finding implies that $H$. jecorina RUT C30 may not be a good source of enzyme production on carbon sources containing starch and other $\alpha$-linked glycans, unless this deficiency is complemented by the corresponding gene from QM 9414.

Another intriguing finding during this study was that the loss of glycerol dehydrogenase GLD2 does not lead to an impaired osmotolerance. Consistent findings have been reported with a gldB-knock out strain of $A$. nidulans [40], 
where it was shown that this strain failed to accumulate glycerol during osmotic stress, but instead accumulated other polyols including D-mannitol, L-arabinitol and Lerythritol. It is therefore possible that other polyol dehydrogenase genes of $\mathrm{H}$. jecorina can compensate for the loss of GLD2. However, the microscopic findings from this study, i.e. that RUT C30 displays a significant swelling of its conidia before it starts to germinate, indicate that osmotic homeostasis is impaired in this strain. A possible explanation for this finding would be that the compensating polyols (L-arabinitol, L-erythritol) are less fast metabolized, and thus lead to an increased osmotic pressure in the spores and delayed germination. The carbon source assimilation experiments also revealed that strain RUT C30 shows an enhanced growth rate on a number of simple carbon sources such as glycerol, $\mathrm{N}$-acetylglucosamine, D-mannitol, D-fructose, D-trehalose, D-mannose, and Dribose. Interestingly, there is evidence that some of them act as catabolite repressing carbon sources in $H$. jecorina (e.g. glycerol, [18]; fructose, [51]; mannose, unpublished data by L. Hartl, C.P. Kubicek and B. Seiboth). The phenotype in RUT C30 may be related to the loss of function of CRE1, and be due to the relief of catabolite repression by these carbon sources within their own catabolic pathways, most likely at the level of uptake. Sugar permeases of $H$. jecorina and other mitosporic fungi are known to be repressed by elevated levels of their substrates [52,53]. This property enables strain RUT C30 to grow faster at high sugar concentrations such as $6 \%$ lactose, a condition employed to make use of its superior cellulase forming capacity [54].

\section{Conclusion}

In conclusion, we have identified a major genomic alteration in the hypercellulolytic mutant strain $H$. jecorina RUT C30, and have been able to correlate several of them with not yet apparent phenotypes of this strain. Likely, insights provided in this paper may only just be the beginning, and further such changes may be found when its genome would be subjected to a more thorough investigation. While the differences between the parent strain and RUT C30 do not interfere with the use of RUT C30 in biotechnology for the production of cellulases, it is clear that the use of this strain for basic research in physiology or molecular genetics is flawed. This is especially true for its use as a "carbon catabolite derepressed" mutant, because the truncation in its CRE1 protein clearly is only one of several more changes compared to its wild-type parent. Such a comparison may only be valid, if the results are compared to the mutant strain NG 14 in which the cre 1 truncation has not yet occurred.

\section{Authors' contributions}

VS performed the molecular work for this study, carried out the microscopy experiments and the investigation of strain NG 14, CG also performed molecular and physiological studies, and ISD performed and evaluated the Biolog phenotype analysis. LH and BS analyzed the cre1 locus. CPK supervised the project, wrote the draft of the manuscript and performed the final submission. All authors approved the final version of the manuscript.

\section{Acknowledgements}

This work was supported by grants from the Austrian Science Foundation (FWF P-19143 and FWF P-1942I) to CPK and BS, respectively. The $H$. jecorina/T. reesei genome sequencing project was funded by the United States Department of Energy.

\section{References}

I. Fierro F, Garcia-Estrada C, Castillo NI, Rodriguez R, Velasco-Conde $T$, Martin JF: Transcriptional and bioinformatic analysis of the $56.8 \mathrm{~kb}$ DNA region amplified in tandem repeats containing the penicillin gene cluster in Penicillium chrysogenum. Fungal Genet Biol 2006, 43:618-629.

2. Keller NP, Turner G, Bennett JW: Fungal secondary metabolism - from biochemistry to genomics. Nature Rev Microbiol 2005, 3:937-947.

3. Rodriguez-Saiz M, Barredo JL, Moreno MA, Fernandez-Canon JM, Penalva MA, Diez B: Reduced function of a phenylacetate-oxidizing cytochrome p450 caused strong genetic improvement in early phylogeny of penicillin-producing strains. J Bacteriol 200I, I 83:5465-547I.

4. Reese ET, Mandels M: Rolling with the times: production and applications of Trichoderma reesei cellulases. Annu Rep Ferm Proc 1984, 7:1-20.

5. El-Gogary S, Leite A, Crivellaro O, El-Dorry H, Eveleigh DE: Trichoderma reesei cellulase - from mutants to induction. In Trichoderma reesei cellulases Edited by: Kubicek CP, Eveleigh DE, Esterbauer H, Steiner W, Kubicek-Pranz EM. Royal Society of Chemistry, Cambridge, UK; 1990:200-21 I.

6. Bailey MJ, Tahtiharju J: Efficient cellulase production by Trichoderma reesei in continuous cultivation on lactose medium with a computer-controlled feeding strategy. Appl Microbiol Biotechnol 2003, 62:156-162.

7. Collen A, Saloheimo M, Bailey M, Penttilä M, Pakula TM: Protein production and induction of the unfolded protein response in Trichoderma reesei strain Rut-C30 and its transformant expressing endoglucanase I with a hydrophobic tag. Biotechnol Bioengin 2005, 89:335-344.

8. Domingues FC, Queiroz JA, Cabral JM, Fonseca LP: The influence of culture conditions on mycelial structure and cellulase production by Trichoderma reesei Rut C-30. Enzyme Microb Technol 2000, 26:394-40I.

9. Levasseur A, Saloheimo M, Navarro D, Andberg M, Monot F, NakariSetala T, Asther M, Record E: Production of a chimeric enzyme tool associating the Trichoderma reesei swollenin with the Aspergillus niger feruloyl esterase $A$ for release of ferulic acid. Appl Microbiol Biotechnol 2006, 73:872-880.

10. Shin CS, Lee JP, Lee JS, Park SC: Enzyme production of Trichoderma reesei Rut C-30 on various lignocellulosic substrates. Appl Biochem Biotechnol 2000, 84:237-245.

II. Zhang Q, Lo CM, Ju LK: Factors affecting foaming behavior in cellulase fermentation by Trichoderma reesei Rut C-30. Bioresour Technol 2007, 98:753-760.

12. Ilmen M, Thrane C, Penttilä M: The glucose repressor gene cre I of Trichoderma: isolation and expression of a full-length and a truncated mutant form. Mol Gen Genet 1996, 25 I:45I-460.

13. Geysens S, Pakula T, Uusitalo J, Dewerte I, Penttilä M, Contreras R: Cloning and characterization of the glucosidase II alpha subunit gene of Trichoderma reesei: a frameshift mutation results in the aberrant glycosylation profile of the hypercellulolytic strain Rut-C30. Appl Environ Microbiol 2005, 71:2910-2924.

14. Mäntylä AL, Rossi KH, Vanhanen SA, Penttilä ME, Suominen PL, Nevalainen KM: Electrophoretic karyotyping of wild-type and mutant Trichoderma longibrachiatum (reesei) strains. Curr Genet 1992, 2 1:471-477. 
15. Carter GL, Allison D, Rey MW, Dunn-Coleman NS: Chromosoma and genetic analysis of the electrophoretic karyotype of Trichoderma reesei: mapping of the cellulase and xylanase genes. Mol Microbiol 1992, 6:2 167-2I 74.

16. Mach RL, Strauss J, Zeilinger S, Schindler M, Kubicek CP: Carbon catabolite repression of xyn I (xylanase I-encoding) gene expression in Trichoderma reesei. Mol Microbiol 1996 , 2 I:|273-|28|.

17. Stricker AR, Steiger MG, Mach RL: XyrI receives the lactose induction signal and regulates lactose metabolism in Hypocrea jecorina. FEBS Lett 2007, 581 :3915-3920.

18. Zeilinger S, Schmoll M, Pail M, Mach RL, Kubicek CP: Nucleosome transactions on the Hypocrea jecorina (Trichoderma reesei) cellulase promoter $\mathrm{cbh} 2$ associated with cellulase induction. Mol Genet Genomics 2003, 270:46-55.

19. Valkonen M, Kalkman ER, Saloheimo M, Penttila M, Read ND, Duncan RR: Spatially segregated SNARE protein interactions in living fungal cells. J Biol Chem 2007, 282:22775-22785.

20. Martinez D, Berka RM, Henrissat B, Saloheimo M, Arvas M, Baker S, Chapman J, Chertkov O, Coutinho PM, Cullen D, Danchin EGJ, Grigoriev IV, Harris P, Jackson M, Kubicek CP, Han CS, Ho I, Larrondo L, Lopez de Leon A, Magnuson J, Merino S, Misra M, Nelson B, Putnam N, Robbertse B, Salamov AA, Schmoll M, Terry A, Thayer N, Westerholm-Parvinen A, Schoch C, Yao C, Barbote R, Xie G, Richardson P, Rokhsar DS, Lucas SM, Rubin EM, Ward M, Brettin TS: Genome sequence analysis of the cellulolytic fungus Trichoderma reesei (syn. Hypocrea jecorina) reveals a surprisingly limited inventory of carbohydrate active enzymes. Nature Biotech 2007, 26:553-560.

21. Mandels MM, Andreotti RE: The cellulose to cellulase fermentation. Proc Biochem 1978, 13:6-13.

22. Chomczynski P, Sacchi N: Single-step method of RNA isolation by acid guanidinium thiocyanate- phenol-chloroform extraction. Anal Biochem 1089, 162:156-159.

23. Seiboth B, Hartl L, Pail M, Fekete E, Karaffa L, Kubicek CP: The galactokinase of Hypocrea jecorina is essential for cellulase induction by lactose but dispensable for growth on D-galactose. Mol Microbiol 2004, 5 I: I 0 I 5-1025.

24. Ausubel FM, Brent R, Kingston RE, Moore DD, Seidman JG, Smith JA, Stuhl K: Current protocols in molecular biology New York: Greene Publishing Associates and Wiley Interscience; 2007.

25. Genome Walker Universal Kit user Manual [http://www.clon tech.com/images/pt/PT3042-I.pdf

26. Pail M, Peterbauer T, Seiboth B, Hametner C, Druzhinina I, Kubicek $C P$ : The metabolic role and evolution of L-arabinitol 4-dehydrogenase of Hypocrea jecorina. Eur J Biochem 2004, 27|: | $864-1872$.

27. Seiboth B, Hartl L, Pail M, Kubicek CP: D-xylose metabolism in Hypocrea jecorina: loss of the xylitol dehydrogenase step can be partially compensated for by lad I-encoded L-arabinitol-4dehydrogenase. Eukaryot Cell 2003, 2:867-875

28. Druzhinina IS, Schmoll M, Seiboth B, Kubicek CP: Global carbon utilization profiles of wild-type, mutant, and transformant strains of Hypocrea jecorina. Appl Environ Microbiol 2006, 72:2126-2133.

29. JGI: Trichoderma reesei v2.0 [http://genome.jgi-psf.org/Trire2/ Trire2.home.html]

30. EMBL-EBI: InterProScan Sequence search [http:// www.ebi.ac.uk/InterProScan/]

31. SMART [http://smart.embl-heidelberg.de]

32. National Center for Biotechnology Information: BLAST [http://www.ncbi.nlm.nih.gov/BLAST/]

33. Thompson JD, Gibson TJ, Plewniak F, Jeanmougin F, Higgins DG: The Clustal $X$ windows interface: flexible strategies for multiple sequence alignment aided by quality analysis tools. Nucleic Acids Res 1997, 25:4876-4882.

34. Nicholas $\mathrm{HB}$ Jr, McClain WH: An algorithm for discriminating sequences and its application to yeast transfer RNA. Comput Appl Biosci 1987, 3:177-|81.

35. Kumar S, Tamura K, Nei M: MEGA3: Integrated software for molecular evolutionary genetics analysis and sequence alignment. Brief Bioinformatics 2003, 5:150-163.

36. Todd RB, Andrianopoulos A: Evolution of a fungal regulatory gene family: the Zn(II)2Cys6 binuclear cluster DNA binding motif. Fungal Genet Biol 1997, 2 I:388-405.
37. Nehls U, Kleber R, Wiese J, Hampp R: Isolation and characterization of a general amino acid permease from the ectomycorrhizal fungus Amanita muscaria. New Phytol 1999, 144:343-349.

38. Kubicek CP, Mühlbauer G, Grotz M, John E, Kubicek-Pranz EM: Properties of a conidial bound cellulase enzyme system from Trichoderma reesei. J Gen Microbiol 1988, I33:1215-1222.

39. Liepins J, Kuorelahti S, Penttilä M, Richard P: Enzymes for the NADPH-dependent reduction of dihydroxyacetone and $D$ glyceraldehyde and L-glyceraldehyde in the mould Hypocrea jecorina. FEBS J 2006, 273:4229-4235.

40. de Vries RP, Flitter SJ, Vondervoort PJ van de, Chaveroche MK, Fontaine T, Fillinger S, Ruijter GJ, d'Enfert C, Visser J: Glycerol dehydrogenase, encoded by gldB is essential for osmotolerance in Aspergillus nidulans. Mol Microbiol 2003, 49:|3|-|4|.

4I. Seidl V, Seiboth B, Karaffa L, Kubicek CP: The fungal STRE-element-binding protein Sebl is involved but not essential for glycerol dehydrogenase (gldI) gene expression and glycerol accumulation in Trichoderma atroviride during osmotic stress. Fungal Genet Biol 2004, 41: I I 32-I I 40.

42. Kubicek CP: From Cellulose to cellulase inducers: facts and fiction. In Proceedings of the second TRICEL symposium on Trichoderma reesei cellulases and other hydrolytic enzymes, Espoo, Finland Edited by: Suominen P, Reinikainen T. Foundation of Biotechnical and Industrial Fermentation Research 8; 1993:181-188.

43. Veneault-Fourrey C, Barooah M, Egan M, Wakley G, Talbot NJ: Autophagic fungal cell death is necessary for infection by the rice blast fungus. Science 2006, 3 I 2:580-583

44. Samuels GJ, Petrini O, Kuhls K, Lieckfeldt E, Kubicek CP: Hypocrea and Trichoderma sect. Longibrachiatum. Stud Mycol 1998 , 4l: $1-54$

45. Kroken S, Glass NL, Taylor JW, Yoder OC, Turgeon BG: Phylogenomic analysis of type I polyketide synthase genes in pathogenic and saprobic ascomycetes. Proc Natl Acad Sci USA 2004, 100:|5670-|5675.

46. Kurahashi H, Inagaki H, Ohye T, Kogo H, Kato T, Emanuel BS: Chromosomal translocations mediated by palindromic DNA. Cell Cycle 2006, 5: 1297-1303.

47. Kurahashi H, Inagaki H, Ohye T, Kogo H, Kato T, Emanuel BS: Palindrome-mediated chromosomal translocations in humans. DNA Repair 2006, 5: I |36-| | 45.

48. Xiang Q, Glass NL: Chromosome rearrangements in isolates that escape from het-c heterokaryon incompatibility in $\mathrm{Neu}$ rospora crassa. Curr Genet 2004, 44:329-338.

49. Hornok L: Chromosomes, karyotype analysis, chromosome rearrangements in fungi. Acta Microbiol Immunol Hung 1999, 46:273-278

50. Kistler HC, Benny U: Autonomously replicating plasmids and chromosome rearrangement during transformation of $\mathrm{Nec}$ tria haematococca. Gene 1992, I I 7:81-89.

51. Hartl L, Kubicek CP, Seiboth B: Carbon signalling by the hexose phosphorylating enzymes of Hypocrea jecorina. ms 2007 in press.

52. Van Kuyk PA, Diderich JA, MacCabe AP, Hererro O, Ruijter G], Visser J: Aspergillus niger mstA encodes a high-affinity sugar/H+ symporter which is regulated in response to extracellular pH. Biochem / 2004, 379:375-383.

53. Ramos AS, Chambergo FS, Bonaccorsi ED, Ferreira AJ, Cella N, Gombert AK, Tonso A, El-Dorry $\mathrm{H}$ : Oxygen- and glucosedependent expression of Trhxtl, a putative glucose transporter gene of Trichoderma reesei. Biochemistry 2006, 45:8184-8192.

54. Allen AL, Mortensen RE: Production of cellulases from Trichoderma reesei in fed batch fermentations from soluble carbon sources. Biotechnol Bioengin I98I, 23:264I-2645. 